\title{
CONHECIMENTOS E OPINIÕES DE ADOLESCENTES SOBRE ABORTAMENTO
}

\author{
KNOWLEDGE AND OPINION OF TEENAGERS ON ABORTION
}

\section{José Roberto da Silva Brêtas ${ }^{\mathrm{a}^{*}}$, Luiz Fabiano Zanatta ${ }^{\mathrm{b}^{*}}$, Silvia Piedade de Moraes ${ }^{\mathrm{c}^{*}}$, Maria José Dias de Freitas ${ }^{\mathrm{d}^{*}}$, Maila Beatriz Goellner ${ }^{\mathrm{e}^{* *}}$}

\author{
abretas@ymail.com, blfzanatta@uenp.edu.br, c'silviapmoraes@hotmail.com, dmjddfreitas@gmail.com, emailabeatriz@gmail.com \\ * Universidade Federal de São Paulo - São Paulo (SP), Brasil \\ **Universidade Estadual do Mato Grosso do Sul - Campo Grande (MS), Brasil \\ Data de recebimento do artigo: 16/04/2017 \\ Data de aceite do artigo: 13/06/2017
}

\section{RESUMO}

Introdução: $\mathrm{O}$ tema abortamento ainda possibilita múltiplas interpretaçóes e representa interesses diversos para as instituiçóes sociais, entre as quais não existe uma posição consensual sobre a questão, mesmo ela estando pautada como um grave problema de saúde pública. Objetivos: Identificar o conhecimento e a opiniáo de adolescentes do ensino médio sobre abortamento, observando quais variáveis se alteram conforme o maior grau de escolarização. Método: Trata-se de um estudo descritivo envolvendo 302 adolescentes de ambos os sexos, na faixa etária entre 14 e 20 anos, que cursavam o ensino médio em três escolas estaduais do município de Embu das Artes (SP). Utilizou-se como instrumento de coleta de dados um questionário semiestruturado de múltipla escolha e autoaplicável em sala de aula. Resultados: Os dados obtidos demonstraram que há forte influência de conceitos religiosos e morais na estruturação dos conhecimentos sobre o tema e que tais conceitos têm modulado as opiniôes sobre a legislação vigente no país. Em relação aos métodos para a realização de abortamento, observou-se maior percentual de adolescentes que conhecem pequenas cirurgias $(50,66 \%)$, seguido por aqueles que citam chá de maconha $(34,43 \%)$ e objetos pontiagudos $(27,48 \%)$. Em relação às fontes de informação sobre abortamento, detectou-se resultados significativos estatisticamente apenas para revista/jornal $(\mathrm{p}=0,001)$ e TV $(\mathrm{p}=0,003)$. Sobre a opiniáo em relaçáo ao tema, 55,63\% dos participantes se colocaram contra a realizaçáo do abortamento e $82,45 \%$ se mostraram favoráveis em casos de gravidez resultante de estupro. Conclusão: A formulação de conhecimentos sobre a temática foi pautada na legalidade, aumentando sua intensidade de acordo com a maior escolarização dos respondentes, enquanto a opiniáo dos participantes refletiu o ideário social dominante.

Palavras-chave: Abortamento; adolescente; direitos reprodutivos; educação sexual; saúde sexual.

\section{ABSTRACT}

Introduction: The topic of abortion still allows multiple interpretations and represents diverse interests for social institutions, among which there is no consensus on the issue, even though it is considered a serious public health problem. Objective: To identify the knowledge and opinion of high school adolescents about abortion, observing which variables change according to the higher level of schooling. Method: This is a descriptive study involving 302 adolescents of both sexes, between the ages of 14 and 20 years old, who attended high school in three state schools in the city of Embu das Artes (São Paulo, Brazil). A semi-structured, multiple-choice, self-administered questionnaire was used as data collection tool in the classroom. Results: The obtained data showed that there is a strong influence of religious and moral concepts in the structuring of knowledge on the subject, which have modulated opinions about the legislation in force in the country. Regarding abortion methods, a higher percentage of adolescents know about minor surgeries $(50.66 \%)$, followed by marijuana tea $(34.43 \%)$ and pointed objects $(27.48 \%)$. Regarding the sources of information on abortion, statistically significant results were detected only for magazine/newspaper $(\mathrm{p}=0.001)$ and TV $(\mathrm{p}=0.003)$. Concerning the opinion on the theme, $55.63 \%$ of the participants were against abortion and $82.45 \%$ were in favor in cases of pregnancy resulting from rape. Conclusion: The formulation of knowledge on the subject was based on legality, increasing its intensity according to the higher schooling of the respondents, while the opinion of the participants reflected the dominant social ideals on the subject.

Keywords: Abortion; adolescents; reproductive rights; sex education; sexual health. 


\section{Introdução}

O enorme número de gestações interrompidas é um problema de saúde pública, devido às repercussôes na saúde da mulher e aos gastos com internaçóes e procedimentos hospitalares, já que o abortamento representa uma das principais causas de morte materna no Brasil. Conceitualmente, "abortamento" é a interrupçáo da gravidez até a $20^{\mathrm{a}}$ ou $22^{\mathrm{a}}$ semana e com o produto da concepção pesando menos que $500 \mathrm{~g}$, sendo que "aborto" é o produto da concepção eliminado ${ }^{1}$.

A Organização Mundial de Saúde (OMS) divulgou a informaçấo de que 21,6 milhôes de abortamentos inseguros ocorreram em 2008, causando a morte de 47 mil mulheres por complicaçóes relacionadas a infecçōes graves, hemorragias resultantes do procedimento, ou devido a danos em órgãos ${ }^{2}$. Estima-se que ocorram, considerando apenas o Brasil, mais de $1 \mathrm{mi}-$ lhão de abortamentos induzidos ao ano, sendo uma das principais causas de morte materna no país ${ }^{1}$. No entanto, "a ilegalidade do abortamento faz com que sua real magnitude seja desconhecida e suas consequências para a saúde das mulheres obscurecidas"3, pois muitos abortamentos sáo realizados clandestinamente, seja no próprio domicílio ou em "clínicas".

Nesse contexto, marcado por altos índices de morbimortalidade e clandestinidade, inserem-se também as adolescentes. Segundo o Sistema de Informações sobre Mortalidade do Sistema Único de Saúde (SIM/ SUS), no ano de 2013 no Brasil, entre a faixa etária de 15 a 19 anos, foram notificados 31.178 casos de abortamento, estratificados segundo as seguintes características: 16.411 internaçôes por "abortamentos espontâneos"; 14.512 "gravidezes que terminaram em abortamento"; e 255 abortamentos realizados em adolescentes por "razões médicas"

Considerando que a mortalidade representa apenas uma fração dessa problemática, os dados referentes à hospitalização por abortamento confirmam sua magnitude. A curetagem pós-abortamento representa o terceiro procedimento obstétrico mais realizado nas unidades de internaçáo da rede pública de serviços de saúde ${ }^{1}$. Destaca-se que, conforme o SIM/SUS ${ }^{4}$, no ano de 2013 , entre a faixa etária de quinze a dezenove anos, foram realizados 172.412 procedimentos de curetagem pós-abortamento puerperal. No entanto, presumi-se que todos os números apresentados até o momento estejam muito abaixo da realidade nacional, devido à subnotificação, justificada pelo fato de as mulheres e adolescentes se sentirem geralmente constrangidas ou amedrontadas para informar o procedimento nos serviços de saúde 5 .
Diante desse viés, ressalta-se que o tema "ainda possibilita múltiplas interpretaçóes e representa interesses diversos para as instituiçóes sociais, não existindo uma posição consensual" ". Historicamente, a questáo vem pautando discussóes que "ultrapassam as fronteiras do universo privado, da vida individual" ${ }^{6}$, passando a integrar discussóes políticas no país, assim como fóruns de discussóes que sistematizam em nível nacional e internacional questóes como direitos sexuais e reprodutivos das mulheres.

Mesmo pautado como um grave problema de saúde pública, que necessita ser enfrentado pela sociedade e pelo Congresso $\mathrm{Nacional}^{7}$, o abortamento ainda representa um tabu, com discursos orientados pela religiosidade, moralidade e ética, promovendo entraves para expansão do diálogo na sociedade, seja no âmbito familiar e nos espaços escolares, seja entre os profissionais da saúde. Assim, a abordagem profissional e a assistência estão permeadas pela concepçáo de crime, excluindo questóes sobre direitos sexuais e reprodutivos e sobre o conjunto de complicaçôes acarretadas pela prática clandestina do procedimento, bem como os fatores sociais envolvidos ${ }^{8}$.

A questão do abortamento está relacionada a aspectos bem mais complexos da vida social brasileira, como o retrocesso em que vive o país perante temas de igualdade de gênero, o que impacta negativamente a formulaçáo de políticas para a saúde da mulher, principalmente quanto aos preconceitos sobre direitos sexuais e reprodutivos, advindos de um longo processo intensificado com o avanço do conservadorismo religioso no governo'. Nesse sentido, sabe-se que, no Brasil, presidentes precisam formar amplas coalizóes para governar, o que pode exigir concessôes aos grupos mais tradicionalistas do Congresso Nacional. Assim, "parlamentares conservadores, especialmente os ligados às igrejas evangélicas e católicas, têm tornado o aborto cada vez mais um foco de suas campanhas e atuação legislativa" ${ }^{10}$.

Recentemente, "a epidemia de Zika renovou as discussóes sobre o direito ao aborto no Brasil. O debate atual é similar às discussóes sobre rubéola que ocorreram em vários países em meados do século XX. No Brasil, contudo, esse debate nunca ocorreu" ${ }^{\prime 10}$. Porém, no início dos anos 1990, havia três projetos de lei (PL) tramitando no congresso que discutiam HIV e aborto, cujo objetivo era expandir o direito ao aborto no Brasil. O PL no 2.023, de 10 de outubro de 1991, e o PL no 3.005 , de 2 de julho de 1992, visavam exclusivamente tornar o aborto legal para mulheres soropositivas, enquanto o PL no 1.174 , de $1^{\circ}$ de agosto de 1991 , objetivava legalizar o procedimento em casos de "enfermidade grave e hereditária" do nascituro, entre os quais os autores incluíam a aids. Já em 2016, o único projeto de lei que diz respeito ao aborto e à zika (PL no 4.396, de 16 
de fevereiro) pretende aumentar a penalidade criminal "quando o aborto for cometido em razão da microcefalia ou qualquer outra anomalia do feto". Nesse sentido, para Camargo ${ }^{10}$, propostas como essa revelam que o Brasil, por meio da dinâmica do Congresso Nacional, tem sofrido mudanças. Há vinte anos, a maioria dos projetos de lei sobre aborto visava a legalização ou ampliação dos direitos das mulheres, por meio de exceçóes. Com o aumento da bancada evangélica esse cenário tem sido revertido e, se antes os defensores não atingiam a aprovação dos projetos, ao menos conseguiam conter maiores restriçôes à interrupção de gravidez e garantiam mais espaço para o debate.

Nesse contexto, o conhecimento e as opiniôes de adolescentes sobre a temática e o modo como se posicionam diante das variáveis que podem levar à decisão de interromper a gravidez tornam-se subsídios para intervenção nos problemas de ordem social e cultural, o que contribui para planejar ações mais eficazes no enfrentamento do problema, tanto no contexto escolar como em saúde pública.

Diante do exposto, este estudo teve como objetivo identificar o conhecimento e a opiniáo de adolescentes do ensino médio sobre aborto, observando quais variáveis se alteram conforme o maior grau de escolarizaçáo.

\section{Método}

Trata-se de um estudo quantitativo descritivo que busca o estabelecimento de relaçóes entre as variáveis, visando levantar opiniốes, atitudes e crenças dos participantes sobre a temática pesquisada ${ }^{11}$. A amostragem populacional se fez por conveniência, já que a realizaçáo deste estudo teve origem nas atividades de campo desenvolvidas com adolescentes e jovens pela equipe de um projeto de extensão universitária em três escolas estaduais de ensino médio, situadas na região de Santo Eduardo, periferia do extremo sul do município da Estância Turística de Embu, São Paulo, limite com o bairro Capão Redondo.

Dessa forma, a amostra foi constituída por 302 adolescentes de ambos os sexos, com idades entre 14 e 20 anos, estudantes dos três anos do ensino médio. Foram adotados como critérios de inclusão: o(a) estudante estar regularmente matriculado(a) em um dos três anos do ensino médio e frequentando uma das três escolas; aceitar livremente, mediante assinatura do termo de assentimento e consentimento de seu responsável, participar da pesquisa.

Para a coleta de dados, utilizou-se um instrumento semiestruturado, autoaplicável e de múltipla escolha, composto por quinze questóes, das quais cinco objetivaram identificar as características sociodemográficas da população e dez buscavam avaliar o conhecimento e a opiniáo dos adolescentes sobre o tema. Ressalta-se como procedimento metodológico para adequação e redimensionamento do instrumento a realização de um pré-teste sobre o questionário piloto, com a participação de cem adolescentes. Destaca-se que tais resultados foram excluídos deste estudo.

$\mathrm{Na}$ análise dos dados, aplicou-se o teste de associação do Qui-quadrado para tabela "2 x 3" (Qui-quadrado com correçáo de Yates). Foram considerados estatisticamente significativos os valores de $p<0,05$. A apresentação de dados é feita por tabelas de contingência, elaboradas mediante as estratificaçóes: $\mathrm{N}$ para total entre as séries do ensino médio (302); n para cada série e valor de P (Qui-quadrado) para detectar a significância da variável, quando comparada entre as séries.

$\mathrm{O}$ estudo foi realizado seguindo as normas para pesquisas envolvendo seres humanos, estabelecidas pela Resolução no 446, de 12 de dezembro de $2012^{12}$, aprovada pelo Comitê de Ética em Pesquisa da Universidade Federal de São Paulo (Unifesp), sob o parecer $n^{\circ}$ 140.411 .

\section{Resultados}

Entre os 302 participantes, observou-se que 138 eram do sexo feminino e 164 do masculino. Em relação à escolaridade, $22 \%$ frequentavam o primeiro ano, $44 \%$ o segundo, e $22 \%$ cursavam o terceiro ano do ensino médio. Quanto à faixa etária, verificou-se que $34 \%$ possuíam idades entre catorze e dezesseis anos incompletos, $61 \%$ entre dezesseis e dezoito anos incompletos e 6\% contavam dezoito a vinte anos completos. Sobre religião, constatou-se que $52 \%$ eram católicos, 36\% evangélicos, $6 \%$ ateus e $6 \%$ adeptos de outras religiōes.

Quando abordados a respeito de "onde adquirem conhecimentos sobre o abortamento", os maiores percentuais entre as oito variáveis foram para escola $(67,54 \%)$, TV $(64,23 \%)$ e internet $(37,08 \%)$. No entanto, ao aplicar o teste de Qui-quadrado, detectou-se significância estatística sobre o conhecimento entre os anos somente para revista/jornal $(\mathrm{p}=0,001)$ e TV $(\mathrm{p}=0,003)$, conforme demonstrado na Tabela 1 .

A Tabela 2 demonstra o conhecimento dos participantes quanto às maneiras de provocar um abortamento. Observou-se maior percentual de adolescentes que citam pequenas cirurgias $(50,66 \%)$, seguidos pelos que mencionam chá de maconha $(34,43 \%)$ e objetos pontiagudos $(27,48 \%)$. Ressalta-se que, entre as variáveis, não se detectou significância estatística sobre o conhecimento entre os anos. 
Tabela 1: Distribuição da população do estudo segundo a fonte de conhecimento sobre o tema abortamento. Embu das Artes, São Paulo, 2011.

\begin{tabular}{|c|c|c|c|c|c|c|c|c|c|}
\hline \multirow[t]{2}{*}{ Variáveis } & \multicolumn{2}{|c|}{$\begin{array}{c}\text { Total } \\
(n=302)\end{array}$} & \multicolumn{2}{|c|}{$\begin{array}{l}\text { Primeira série do } \\
\text { ensino médio }\end{array}$} & \multicolumn{2}{|c|}{$\begin{array}{l}\text { Segunda série do } \\
\text { ensino médio }\end{array}$} & \multicolumn{2}{|c|}{$\begin{array}{l}\text { Terceira série do } \\
\text { ensino médio }\end{array}$} & \multirow[t]{2}{*}{$P$ valor } \\
\hline & $\mathbf{n}$ & $\%$ & $\mathbf{n}$ & $\%$ & n & $\%$ & $\mathbf{n}$ & $\%$ & \\
\hline Amigos & 101 & 33,44 & 19 & 29,23 & 39 & 29,55 & 43 & 40,95 & NS* \\
\hline Igreja & 56 & 18,54 & 12 & 18,46 & 18 & 13,64 & 26 & 24,76 & NS \\
\hline Escola & 204 & 67,54 & 49 & 75,38 & 89 & 67,42 & 66 & 62,86 & NS \\
\hline Revista/jornal & 102 & 33,77 & 14 & 21,54 & 39 & 29,55 & 49 & 46,67 & 0,001 \\
\hline Internet & 112 & 37,08 & 18 & 27,69 & 49 & 37,12 & 45 & 42,86 & NS \\
\hline Família & 111 & 36,75 & 23 & 35,38 & 47 & 35,61 & 41 & 39,05 & NS \\
\hline TV & 194 & 64,23 & 34 & 52,31 & 80 & 60,61 & 80 & 76,19 & 0,003 \\
\hline Palestras & 3 & 0,99 & - & - & - & - & 3 & 2,86 & - \\
\hline Não responderam & 1 & 0,33 & - & - & - & - & 1 & 0,95 & - \\
\hline
\end{tabular}

Legenda: NS: Não significativo; * Possibilitavam mais de uma resposta.

Tabela 2: Distribuição da população do estudo sobre o conhecimento das maneiras de provocar aborto. Embu das Artes, São Paulo, 2011.

\begin{tabular}{|c|c|c|c|c|c|c|c|c|c|}
\hline \multirow[t]{2}{*}{ Variáveis } & \multicolumn{2}{|c|}{$\begin{array}{c}\text { Total } \\
(n=302)\end{array}$} & \multicolumn{2}{|c|}{$\begin{array}{l}\text { Primeira série do } \\
\text { ensino médio }\end{array}$} & \multicolumn{2}{|c|}{$\begin{array}{l}\text { Segunda série do } \\
\text { ensino médio }\end{array}$} & \multicolumn{2}{|c|}{$\begin{array}{l}\text { Terceira série do } \\
\text { ensino médio }\end{array}$} & \multirow[t]{2}{*}{ P valor } \\
\hline & n & $\%$ & n & $\%$ & n & $\%$ & $\mathbf{n}$ & $\%$ & \\
\hline Chá caseiro & 62 & 20,52 & 13 & 20 & 39 & 14,39 & 30 & 28,57 & NS* \\
\hline Chá de maconha & 104 & 34,43 & 17 & 26,15 & 49 & 37,12 & 38 & 36,19 & NS \\
\hline Objetos pontiagudos & 83 & 27,48 & 18 & 27,69 & 28 & 21,21 & 37 & 35,24 & NS \\
\hline Pequenas cirurgias & 153 & 50,66 & 33 & 50,77 & 64 & 48,48 & 56 & 53,33 & NS \\
\hline Não conhece & 39 & 12,91 & 10 & 15,38 & 12 & 9,09 & 17 & 16,19 & NS \\
\hline
\end{tabular}

Legenda: NS: Não significativo; * Possibilitavam mais de uma resposta.

Quando os adolescentes foram interrogados sobre "em que casos apoiariam a realização do abortamento", detectou-se os maiores percentuais para casos de estupro $(82,45 \%)$, outras situaçóes, que incluíram risco de morte para a mãe durante a gestação $(14,90 \%)$, gravidez de mães muitos jovens e feto com má formação. Há ainda, entre esse percentual, adolescentes que disseram não apoiar o abortamento em qualquer tipo de situação. Destaca-se que nessa investigação o teste de Qui-quadrado apresentou significância nas respostas para mães sem condiçóes de criar os filhos $(p=<0,000)$ e nos casos de estupro $(p=0,046)$, verificados na Tabela 3 .
Os resultados obtidos por meio da interrogação "Você não apoiaria alguém a realizar o abortamento, por quê?" também estáo na Tabela 3. Verificou-se que 55,63\% dos adolescentes sustentavam a não realização do abortamento por considerarem que a vida é um bem precioso; $49,66 \%$ associaram a questão da possibilidade de prevenção da gravidez não planejada, apontando a existência de preservativos; e 49,01\% não apoiariam por considerarem o ato como "um assassinato". Nota-se que o teste estatístico apresenta significância entre os anos quando os adolescentes citam a falta de apoio ao aborto associada à questão de amor aos filhos $(\mathrm{p}=0,017)$, ao sentido de assassinato $(\mathrm{p}=0,035)$ e à ideia de algo ruim $(\mathrm{p}=0,006)$.

Tabela 3: Distribuição da população do estudo segundo a opinião dos escolares sobre casos em que apoiariam ou não a realização do abortamento. Embu das Artes, São Paulo, 2011.

\begin{tabular}{|c|c|c|c|c|c|c|c|c|c|}
\hline \multirow[t]{2}{*}{ Variáveis } & \multicolumn{2}{|c|}{$\begin{array}{c}\text { Total } \\
(n=302)\end{array}$} & \multicolumn{2}{|c|}{$\begin{array}{l}\text { Primeira série do } \\
\text { ensino médio }\end{array}$} & \multicolumn{2}{|c|}{$\begin{array}{l}\text { Segunda série do } \\
\text { ensino médio }\end{array}$} & \multicolumn{2}{|c|}{$\begin{array}{c}\text { Terceira série do } \\
\text { ensino médio }\end{array}$} & \multirow[t]{2}{*}{$P$ valor } \\
\hline & $\mathbf{n}$ & $\%$ & $\mathbf{n}$ & $\%$ & $\mathbf{n}$ & $\%$ & $\mathbf{n}$ & $\%$ & \\
\hline $\begin{array}{l}\text { Motivos que levam a apoiarem o } \\
\text { abortamento* } \\
\text { Casos de estupro }\end{array}$ & 249 & 82,45 & 47 & 72,31 & 114 & 86,36 & 88 & 83,81 & 0,046 \\
\hline Quando a mãe corre risco de morte & 228 & 75,49 & 49 & 75,38 & 102 & 77,27 & 77 & 73,33 & NS* \\
\hline
\end{tabular}


Tabela 3: Continuação.

\begin{tabular}{|c|c|c|c|c|c|c|c|c|c|}
\hline \multirow[t]{2}{*}{ Variáveis } & \multicolumn{2}{|c|}{$\begin{array}{c}\text { Total } \\
(\mathrm{n}=302)\end{array}$} & \multicolumn{2}{|c|}{$\begin{array}{l}\text { Primeira série do } \\
\text { ensino médio }\end{array}$} & \multicolumn{2}{|c|}{$\begin{array}{l}\text { Segunda série do } \\
\text { ensino médio }\end{array}$} & \multicolumn{2}{|c|}{$\begin{array}{l}\text { Terceira série do } \\
\text { ensino médio }\end{array}$} & \multirow[t]{2}{*}{ P valor } \\
\hline & $\mathbf{n}$ & $\%$ & $\mathbf{n}$ & $\%$ & $\mathbf{n}$ & $\%$ & $\mathbf{n}$ & $\%$ & \\
\hline Mãe sem condiçôes de cuidar do filho & 27 & 8,94 & 15 & 23,08 & 9 & 6,82 & 3 & 2,86 & $<0,000$ \\
\hline Gravidez indesejada & 18 & 5,96 & 9 & 13,85 & 5 & 3,79 & 4 & 3,81 & 0,010 \\
\hline Pai não assume & 9 & 2,98 & 4 & 6,15 & 4 & 3,03 & 1 & 0,95 & NS \\
\hline Gravidez não planejada & 9 & 2,98 & 4 & 6,15 & 4 & 3,03 & 1 & 0,95 & NS \\
\hline Em qualquer circunstância & 5 & 1,65 & 2 & 3,08 & 2 & 1,52 & 1 & 0,95 & - \\
\hline \multicolumn{10}{|l|}{$\begin{array}{l}\text { Motivos que levam a náo apoiarem } \\
\text { o abortamento* }\end{array}$} \\
\hline É um crime & 213 & 70,52 & 35 & 53,85 & 90 & 68,18 & 88 & 83,81 & $<0,000$ \\
\hline Amor aos filhos & 101 & 33,44 & 26 & 40 & 51 & 38,64 & 24 & 22,86 & 0,017 \\
\hline $\begin{array}{l}\text { Possibilidade de entregar o filho para } \\
\text { adoçáo após o nascimento }\end{array}$ & 65 & 21,52 & 13 & 20 & 31 & 23,48 & 21 & 20 & NS \\
\hline Seria um assassinato & 148 & 49,01 & 27 & 41,54 & 59 & 44,70 & 62 & 59,05 & 0,035 \\
\hline Contra ato divino & 101 & 33,44 & 27 & 41,54 & 41 & 31,06 & 33 & 31,43 & NS \\
\hline Vida é um bem precioso & 168 & 55,63 & 31 & 47,69 & 73 & 55,30 & 64 & 60,95 & NS \\
\hline Porque é ruim & 103 & 34,10 & 29 & 44,62 & 50 & 37,88 & 24 & 22,86 & 0,006 \\
\hline
\end{tabular}

Legenda: NS: Não significativo; * Possibilitavam mais de uma resposta.

\section{Discussão}

Os resultados do estudo, obtidos por meio de média ponderal entre os anos do ensino médio demonstraram que $94,7 \%$ dos participantes reconhecem o aborto como uma interrupção da gravidez que pode ocorrer de forma espontânea ou provocada, sendo que, para $88 \%$ dos participantes, tratava-se de um procedimento ilegal, e 85,7 $\%$ pontuavam que o aborto é permitido no Brasil quando resultante de estupro e quando a gravidez coloca em risco a vida materna. Destacou-se que os conhecimentos dos participantes condizem com o que é proposto pelo artigo 128 do Código Penal de 1940, que prevê o abortamento legalizado para gestações resultantes de estupro e em caso de risco de morte para a mulher ${ }^{13}$.

Não foram apresentados pelos participantes do estudo conhecimentos sobre o aborto de anencéfalos. Conforme a Resolução do Conselho Federal de Medicina no 1.989, de 14 de maio de 2012, Art. 10 "Na ocorrência do diagnóstico inequívoco de anencefalia o médico pode, a pedido da gestante, independente de autorização do Estado, interromper a gravidez"14.

Observou-se que os conhecimentos dos participantes desta pesquisa sobre o tema aborto foi pautado predominantemente por questóes morais, legais e éticas. No entanto, não se verificou mençóes sobre o abortamento como um exercício de autonomia reprodutiva das mulheres ${ }^{15}$.

Destacou-se que as constataçóes frente às variáveis sobre conhecimentos e opiniōes nesta pesquisa, quando testadas sua significância entre a maior escolarização, demonstraram que a maior escolaridade indica que outros "valores" se interpóem, aumentando o conhecimento sobre a temática e a possibilidade de formularem diferentes opinióes. Corroborando com este resultado, a Unesco ${ }^{16}$ afirma que quanto maior a escolaridade, maiores são os conhecimentos relacionados aos saberes sobre sexualidade.

Conforme verificado na Tabela 1 , a escola foi apontada por $67,54 \%$ dos participantes do estudo, como o ambiente em que mais adquirem conhecimentos sobre o tema aborto. No entanto, não se constatou significativo aumento de conhecimento entre a maior escolarização para esta variável. Os resultados ressaltam a necessidade da educação em sexualidade enquanto forma de promoção de saúde ${ }^{16}$ e a possibilidade desta intervenção promover e ser significativa na aquisição de conhecimentos de seus escolares, ao avançarem nos períodos de escolarização.

Nesse contexto, é fundamental que essa agência socializadora e promotora de conhecimentos possa informar e reduzir os fatores de exposição a riscos para os adolescentes e que ela interfira diretamente sobre as vulnerabilidades individuais de seus escolares ao ser capaz de gerar conhecimentos que seráo transformados em atitudes e práticas protetivas ${ }^{17}$.

No entanto, é necessário que esta prática seja permeada por informaçóes sobre o conhecimento do próprio corpo, inter-relacionamentos, práticas sexuais, diversidade de gênero, respeito ao próximo, prevenção às infecçôes sexualmente transmissíveis (IST), entre outras, pois o entendimento destas manifestaçôes da sexualidade são complexidades que envolvem a gravidez e o aborto, permitindo a reflexão, reconsideração ou reafirmaçâo de opinióes sobre a temática. 
A televisão apresentou-se como o segundo local mais representativo para aquisição de conhecimentos sobre o aborto, apontado por $64,23 \%$ dos participantes e seguido pela internet, com $37,08 \%$. No entanto, quando realizado o teste de significância, o acrescimento de conhecimento, de acordo com a maior escolarização, foi representativo somente para a televisão.

Revista/jornal e amigos obtiveram porcentagens muito próximas quando apontados como fontes de conhecimentos para os escolares, com percentuais de $33,77 \%$ e $33,44 \%$, respectivamente. No entanto, somente a variável "revistas e jornais" constatou significância entre a maior escolarização dos participantes.

Os resultados reafirmam o quanto a mídia tem se apresentado como meio privilegiado de informaçóes sobre práticas de aborto ${ }^{18}$. Não obstante, formas caseiras e também inseguras veiculam tanto pela mídia impressa quanto pela internet, sendo muitas vezes uma compilação da outra. Na maioria dos casos, sobretudo na televisão e revistas de circulação nacional (geralmente femininas e com chamadas de moda, dietas, amor e beleza que circulam largamente entre adolescentes), estas informaçôes estão sutilmente sendo repassadas por meio de biografias de mulheres que abortaram e "cuidados" com a saúde como, por exemplo, o uso indiscriminado de alguns chás.

Ressalta-se que a família ocupou entre os participantes a quarta posição para o local de aquisiçáo de conhecimentos, citado por $36,75 \%$ dos participantes, náo tendo esta variável obtido teste significativo para maior escolarização. Observa-se que para os participantes deste estudo a família não é o principal ambiente para obter conhecimento referente à temática do abortamento, isso se deve por ser um assunto difícil e delicado, com tabus e controvérsias, marcados por conceitos que moldam a sociedade.

De acordo com as práticas de aborto, geralmente são acompanhadas com a justificativa de medo da reação dos pais e não aceitação do companheiro à gravidez e ao filho, demonstrando que na maioria das vezes a família não toma conhecimento da gravidez, motivo que pode levar a adolescente a práticas inseguras de aborto ${ }^{19}$.

A Tabela 2 apresentou quais maneiras de provocar o aborto são conhecidas pelos participantes. De acordo com os dados obtidos, o principal tipo de aborto que conheciam foi o "aborto induzido", pois os maiores percentuais foram representados por pequenas cirurgias $(50,66 \%)$, chá de maconha $(34,43 \%)$, objetos pontiagudos $(27,48 \%)$ e chá caseiro $(20,52 \%)$. Ressalta-se a presença do chá de maconha, pois não foram encontrados estudos que apresentam o uso deste método como técnica abortiva. Acredita-se que os participantes promoveram associação entre as propriedades tóxicas da planta, com a possibilidade desta ser capaz de desencadear abortamento. Dessa forma, pensamos que se trata de uma representação coletiva, pautada no conhecimento do senso comum.

Destaca-se que, sobre as maneiras de provocar o aborto, nenhuma variável obteve significância entre a maior escolarização dos participantes. Demonstrando o quanto a presença dessas formas de provocar aborto é perpetuada coletivamente entre o senso comum e manifestada nas formas usuais de abortamento. Entretanto, sabe-se que o aborto é praticado com o uso de meios diversos, muitas vezes induzidos pela própria mulher ou realizados em condições inseguras, em geral acarretando consequências danosas à saúde, podendo, inclusive, levar à morte ${ }^{1}$.

Vale ressaltar que os(as) participantes do estudo citaram práticas abortivas envolvendo chás caseiros, material contundente e intervenções cirúrgicas, mas não citaram produtos químicos como o Cytotec.

As práticas e os percursos adotados pelas mulheres para abortar mudaram nas duas últimas décadas no Brasil. Até os anos 1980, sondas, substâncias cáusticas ou objetos perfurantes eram métodos muito utilizados, o que resultava em alta morbimortalidade relacionada ao aborto inseguro. O misoprostol (Cytotec), droga introduzida no mercado farmacológico para tratamento de úlcera gástrica, foi logo percebido em razáo de seu potencial abortivo. A partir da década de 1990, vários estudos constataram que o misoprostol era o agente abortivo em mais da metade dos $\operatorname{casos}^{20}$.

Ainda nesse contexto, vale citar o informe de outubro de 2008 do Instituto Guttmacher ${ }^{21}$, que apontou como métodos usuais em abortamentos inseguros a inserção de preparos herbais na vagina, chás, saltos de escadas ou telhados, além de uso de paus e ossos de frango, dentre outros objetos de risco. A prática do aborto inseguro por meio de chás, objetos pontiagudos e curetagens em clínicas particulares são presentes em maior número dos casos do primeiro aborto, quase sempre relacionados à adolescência ${ }^{22}$.

Tais dados corroboram com a ideia de que é na adolescência, quando há instabilidade financeira, informaçôes precárias e pouca autonomia, que a vulnerabilidade relacionada ao aborto é muito maior.

$\mathrm{Na}$ Tabela 3 foram apresentadas as opiniōes dos participantes sobre os motivos que os levariam a apoiarem ou não a realização de aborto. Sobre os motivos citados para apoiarem o aborto, verifica-se que $82,45 \%$ dos participantes seriam favoráveis em casos de gravidez resultante de estupro. Este dado apresentou teste estatisticamente significativo quando relacionado entre os anos 
do ensino médio, o que demonstra que a formulação de conceitos pautados na ética e legalidade tornam-se maiores de acordo com o maior tempo de escolarizaçáo.

Corroborando com o resultado de Duarte et al. ${ }^{23}$, que avaliou a opiniáo de magistrados e promotores e constatou que $80,6 \%$ dos participantes também se posicionavam como favoráveis ao aborto em casos de gravidez resultante de estupro. Destaca-se que os escolares, ao se posicionarem táo representativamente a favor do aborto decorrente de casos de estupros, demonstram, mesmo que indiretamente, conhecer o que estabelece o Código Penal Brasileiro ${ }^{13}$, pois nos termos da lei o abortamento é crime tipificado, com exceção das situaçôes previstas pelos incisos I e II do artigo 128, que estabelecem o direito de interrupção de gravidez decorrente de estupro.

Outro fator significativamente representativo entre os anos, indicado pelos participantes do estudo ao opinarem como favoráveis à realização do abortamento, foi o apoio à prática em casos nos quais a futura mãe não tenha condiçóes de cuidar do filho. De acordo com Pinheiros e Arantes ${ }^{24}$, o projeto de vida na adolescência ocupa uma parte razoável do tempo desse segmento e mobiliza afetos e valores. Para os adolescentes, o projeto de vida é organizado mentalmente de forma linear e uma gravidez nesse período tenderia a mudanças ou até mesmo ao fracasso de seu futuro, de forma que, mesmo aceitando a gravidez, ela se torne náo desejada.

Apresentaram-se como significativos os dados que apontam como não favoráveis ao abortamento "o amor aos filhos", "o sentido de assassinato" e "a realização de algo ruim". Para Hanschmidt et al. ${ }^{25}$, o medo do estigma e do julgamento social tem sido um dos fatores mais impactantes sobre as mulheres. Há uma forte associação entre o autojulgamento e a culpa, levando a um aumento da aflição psicológica. A culpa é tão intensa que transita em todas as fases pensar na possibilidade do aborto, estabelecer prós e contras e decidir ou seja, mesmo que a decisão não seja pelo aborto, a culpa existe pelo fato de ter conjecturado tal possibilidade.

\section{Conclusão}

Pode-se identificar que a principal fonte de informação dos participantes deste estudo para formulação de conhecimentos e opinióes sobre aborto relacionam-se às informações transmitidas através das mídias de comunicação (impressas ou não). Todavia, o estudo reafirma o quanto os valores morais e religiosos têm impactado a construção destes conhecimentos e são marcados por nuances sócio-históricas de cada período. Esta pesquisa evidenciou que idade superior e maior escolarização são significativas para a formulaçáo de conceitos sobre o aborto.
Em relação à opinião dos(as) participantes, os resultados apresentados neste estudo evidenciaram o ideário social dominante sobre o tema, nos levando a pensar que é mais provável que os brasileiros apoiem restriçôes ao acesso a abortamentos legais e seguros do que a legalização da prática.

Entretanto, a construção dos conhecimentos e opiniôes sobre aborto são estruturadas por saberes previamente construídos. Os discursos (re)produzidos pelas mídias quanto a aborto geralmente: 1 - possuem cunho religioso, o que associa a legalizaçáo do abortamento a uma proposta violenta e assassina da vida de um ser inocente; 2 Amparam-se no discurso sanitário da redução de danos que, por meio da legalização do aborto, minimizaria os impactos da criminalizaçáo dessa prática; 3 São impregnados pelo discurso sanitário higienista que procura manter a criminalização das mulheres para não disseminar a irresponsabilidade do abortamento; 4 Não reconhecem o discurso feminista, que vê na legalização do abortamento a possibilidade de rompimento com a normativa patriarcal e machista; 5 Respeitam e acatam o discurso eleitoreiro no qual a legalização do aborto é objeto de negociação de votos e de alianças com grupos distintos da sociedade.

O discurso da mídia sobre o tema deveria ser pautado, minimamente, com a posição de neutralidade na apresentação dos fatos. Entretanto, o enfoque acaba se baseando na polêmica e no tabu, o que implica na necessidade de reflexão sobre esse veículo e sobre sua interferência provável na legitimação de uma prática social que tem aceitação quando ocorre de forma silenciosa e invisível, nos modos hegemônicos de agir e pensar.

Destaca-se a adoçáo do método como um limitador do estudo. Tratando-se de uma proposta quantitativa, a compreensão de processos sociais, subjetividades e singularidades mais específicas não podem ser interpretadas. Dessa forma, sugere-se a realização de estudos qualitativos para melhor compreensão do fenômeno. Todavia, considera-se que o objetivo desta pesquisa foi atingido plenamente, pois conseguiu identificar aspectos do conhecimento e da opinião dos(as) participantes sobre o tema abortamento.

\section{Referências}

1. Brasil. Ministério da Saúde. Secretaria de Atenção à Saúde. Departamento de Açóes Programáticas Estratégicas. Atenção humanizada ao abortamento: norma técnica. 2a ed. Brasília, DF: Ministério da Saúde; 2011. (Direitos Sexuais e Direitos Reprodutivos, Caderno no. 4).

2. Organización Mundial de la Salud. Aborto sin riesgos: guía técnica y de políticas para sistemas de salud. 2a ed. Uruguay: OMS; 2012. 
3. Pilecco FB, Knauth DR, Vigo A. Aborto e coerção sexual: o contexto de vulnerabilidade entre mulheres jovens. Cad Saúde Pública. 2011;27(3):427-39.

4. Brasil. Sistema Único de Saúde. Sistema de Informações sobre Mortalidade. Painel de monitoramento da mortalidade materna [Internet]. Brasília, DF; 2013 [citado em 2015 mar 12] Sistema de Informaçóes sobre Mortalidade. Painel de monitoramento da mortalidade materna. Disponível em: https://goo.gl/v4cT3Q

5. Brasil. Ministério da Saúde. Secretaria de Ciência, Tecnologia e Insumos Estratégicos. Departamento de Ciência e Tecnologia. Aborto e saúde pública no Brasil: 20 anos. Brasília: Ministério da Saúde; 2009. (Série B. Textos Básicos de Saúde).

6. Mortari CLH, Martini JG, Vargas MA. Representaçóes de enfermeiras sobre o cuidado com mulheres em situação de aborto inseguro. Rev Esc Enferm USP. 2012;46(4):914-21.

7. Diniz D. Aborto e saúde pública no Brasil. Cad Saúde Pública. 2007;23(9):1992-3.

8. Vasconcelos M. Corpo, sexualidade e aborto: o jogo político de significaçóes. Rev Grifos. 2004;(16):95-127.

9. Zanatta LF, Grein MI, Álvarez-Dardet C, Moraes SP, Brêtas JRS, Ruiz-Cantero MT, et al. Igualdade de gênero: por que o Brasil vive retrocessos? Cad Saúde Pública. 2016;32(8):1-2.

10. Camargo TMCR. O debate sobre aborto e zika: liçóes da epidemia de aids. Cad Saúde Pública. 2016;32(5):1-3.

11. Gil, AC. Métodos e técnicas de pesquisa social. São Paulo: Atlas; 2006.

12. Brasil. Conselho Nacional de Saúde. Resoluçáo no 466, de 12 de dezembro de 2012. Aprova as diretrizes e normas regulamentadoras de pesquisas envolvendo seres humanos [Internet]. Diário Oficial da União. Brasília, n. 12, p. 59, 13 jun 2013 [citado em 2015 nov 15]. Disponível em: https:/goo.gl/ik9llL

13. Brasil. Ministério da Saúde. Secretaria de Atenção à Saúde. Departamento de Açóes Programáticas Estratégicas. Área Técnica de Saúde da Mulher. Magnitude do aborto no Brasil: aspectos epidemiológicos e socioculturais: abortamento previsto em lei em situações de violência sexual. Brasília, DF: Ministério da Saúde; 2008.

14. Conselho Federal de Medicina. Resolução no 1.989 , de 14 de maio de 2012. Dispóe sobre o diagnóstico de anencefalia para antecipação terapêutica e dá outras providências. Diário Oficial da União. Brasília, DF; 14 maio 2012. Seção I, p. 308-309.

15. Diniz D, Corrêa M, Squinca F, Braga KS. Aborto: 20 anos de pesquisas no Brasil. Cad Saúde Pública. 2009;25(4):939-42.

16. Unesco. Orientação técnica internacional sobre educação em sexualidade: uma abordagem baseada em evidências para escolas, professores e educadores em saúde. Paris: Unesco; 2010. (Razóes em favor da educação em sexualidade, vol. 1)

17. Ayres JRCM, França Junior I, Calazans GJ, Saletti Filho HC. O conceito de vulnerabilidade e as práticas de saúde: novas perspectivas e desafios. In: Czeresnia D, Freitas CM, organizadores. Promoção da saúde: conceitos, reflexôes, tendências. Rio de Janeiro: Fiocruz; 2003. p. 117-39.

18. Diniz D, Castro R. O comércio de medicamentos de gênero na mídia impressa brasileira: misoprostol e mulheres. Cad Saúde Pública. 2011;27(1):94-102.

19. Correia, DS, Cavalcante JC, Egito EST, Maia EMC. Prática do abortamento entre adolescentes: um estudo em dez escolas de Maceió (AL, Brasil). Ciênc Saúde Coletiva. 2011;16(5):2469-76.

20. Diniz D, Madeiro A. Cytotec e aborto: a polícia, os vendedores e as mulheres. Ciênc Saúde Coletiva. 2012;17(7):1795-804.

21. The Alan Guttmacher Institute. Facts on induced abortion worldwide [Internet]. New York: The Alan Guttmacher Institute; 2008 [citado em 2013 nov 17]. Disponível em: https://goo.gl/cPKjXC

22. Diniz D, Medeiros M. Itinerários e métodos do aborto ilegal em cinco capitais brasileiras. Ciênc Saúde Coletiva. 2012;17(7):1671-81.

23. Duarte GA, Osis MJD, Faúndes A, Sousa MH. Aborto e legislação: opiniấo de magistrados e promotores de justiça brasileiros. Rev Saúde Pública. 2010;44(3):406-20.

24. Pinheiro VPG, Arantes VA. Values and feelings in young Brazilians purposes. Paideia (Ribeirão Preto). 2015;25(61):201-9.

25. Hanschmidt F, Linde K, Hilbert A, Riedel-Heller SG, Kersting A. Abortion stigma: a systematic review. Perspect Sex Reprod Health. 2016;48(4):169-77.

\section{Como citar este artigo:}

Silva JR, Zanatta LF, Moraes SP, Freitas MJD, Goellner MB. Conhecimentos e opiniōes de adolescentes sobre abortamento. Rev. Aten. Saúde. 2017;15(53):20-27. 